\title{
Thyrotropin-Releasing Hormone Analogue
}

National Cancer Institute

\section{Source}

National Cancer Institute. Thyrotropin-Releasing Hormone Analogue. NCI Thesaurus.

Code C76367.

Any structural or functional analogue that mimics the physiological actions of thyrotropin-releasing hormone (TRH). Although TRH analogues appear to have a minimal influence on the biosynthesis of TSH, they seem to exert various neuromodulating activities, such as central nervous system-stimulating, analeptic, analgesic, antidepressant, and neuroprotective effects. 